\title{
Química atmosférica na Amazônia: A floresta e as emissões de queimadas controlando a composição da atmosfera amazônica.
}

\author{
Paulo ARTAXO ${ }^{1}$; Luciana V. GATTI ${ }^{2}$; Ana M. Córdova LEAL $^{2}$ Karla M. LONGO ${ }^{3}$; Saulo R. de FREITAS 3 ; \\ Luciene L. LARA ${ }^{4}$; Theotonio M. PAULIQUEVIS ${ }^{1}$; Aline S. PROCÓPIO ${ }^{1}$; Luciana V. RIZZO ${ }^{1}$.
}

\begin{abstract}
RESUMO
Entender os processos naturais que regulam a composição da atmosfera é crítico para que se possa desenvolver uma estratégia de desenvolvimento sustentável na região. As grandes emissões de gases e partículas durante a estação seca provenientes das queimadas alteram profundamente a composição da atmosfera amazônica na maior parte de sua área. As concentrações de partículas de aerossóis e gases traço aumentam por fatores de 2 a 8 em grandes áreas, afetando os mecanismos naturais de uma série de processos atmosféricos na região amazônica. Os mecanismos de formação de nuvens, por exemplo, são profundamente alterados quando a concentração de núcleos de condensação de nuvens (NCN) passa de 200 a $300 \mathrm{NCN} / \mathrm{cm}^{3}$ na estação chuvosa para 5.000 -

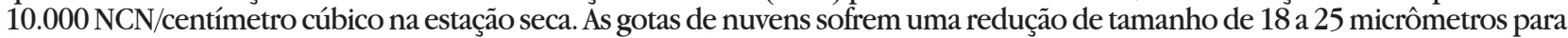
5 a 10 micrômetros, diminuindo a eficiência do processo de precipitação e suprimindo a formação de nuvens. A concentração de ozônio, um gás importante para a saúde da floresta amazônica passa de cerca de 12 partes por bilhão em volume (ppb) (concentração típica ao meio do dia na estação chuvosa) para valores em regiões fortemente impactadas por queimadas de até 100 ppb, nível que pode ser fitotóxico para a vegetação. O balanço de radiação é fortemente afetado, com uma perda líquida de até $70 \%$ da radiação fotossinteticamente ativa na superfície.
\end{abstract}

PALAVRAS CHAVE

Partículas de aerossóis, nuvens, precipitação, química atmosférica, gases traço, ozônio.

\section{Atmospheric Chemistry in Amazonia: The forest and the biomass burning emissions controlling the composition of the Amazonian atmosphere.}

\begin{abstract}
The understanding of the natural processes that regulate atmospheric composition in Amazonia is critical to the establishment of a sustainable development strategy in the region. The large emissions of trace gases and aerosols during the dry season, as a result of biomass burning, profoundly change the composition of the atmosphere in most of its area. The concentration of trace gases and aerosols increases by a factor of 2 to 8 over large areas, affecting the natural mechanisms of several key atmospheric processes in the region. Cloud formation mechanisms, for instance, are strongly affected when the concentration of cloud condensation nuclei (CCN) changes from 200-300 CCN/cc in the wet season to 5,000-10,000 CCN/cc in the dry season. The cloud droplet radius is reduced from values of 18 to 25 micrometers in the wet season to 5 to 10 micrometers in the dry season, suppressing cloud formation and the occurrence of precipitation under some conditions. Ozone is a key trace gas for changes in the forest health, with concentrations increasing from 12 partsper billion (ppb), at the wet season, to values as bigh as $100 \mathrm{ppb}$ (in the dry season in areas strongly affected by biomass burning emissions). At this level, ozone could be damaging the vegetation in regions far from the emissions. The atmospheric radiation balance is also strongly affected, with a net loss of up to $70 \%$ of photosynthetic active radiation at the surface.
\end{abstract}

\section{KEYWORDS}

Aerosol particles, clouds, precipitation, atmospheric chemistry, trace gases, ozone.

\footnotetext{
${ }^{1}$ Instituto de Física, Universidade de São Paulo, Rua do Matão, Travessa R, 187, CEP 05508-900, São Paulo, S. P., Brasil. E-mail: artaxo@if.usp.br.

${ }^{2}$ IPEN - Instituto de Pesquisas Energéticas e Nucleares - Laboratório de Química Atmosférica, Av. Lineu Prestes, 2242; Cidade Universitária, CEP 05508-900, São Paulo, S.P., Brasil.E-mail: lvgatti@net.ipen.br.

${ }^{3}$ CPTEC/INPE-Centro de Previsão de Tempo e Mudanças Climáticas, Instituto Nacional de Pesquisas Espaciais. Rodovia Presidente Dutra, km 40, SP-RJ, CEP 12630-000, Cachoeira Paulista, SP, Brasil. E-mail: sfreitas@cptec.inpe.br.

${ }^{4}$ CENA/USP-Laboratório de Ecologia Isotópica, Centro de Energia Nuclear na Agricultura, Universidade de São Paulo. Avenida Centenário 303, CEP 13400-970, Piracicaba, S. P., Brasil. E-mail: luciene@cena.usp.br.
} 


\section{ACTA \\ AMAZONICA}

QUÍMICA ATMOSFÉRICA NA AMAZÔNIA: A FLORESTA E AS EMISSÕES

DE QUEIMADAS CONTROLANDO A COMPOSIÇÃO DA ATMOSFERA AMAZÔNICA

\section{INTRODUÇÃO}

A região amazônica tem sofrido nas últimas décadas significativa mudança no padrão de uso do solo, através de intenso processo de ocupação humana (Nobre et al., 1996, Davidson \& Artaxo, 2004, Artaxo \& Silva Dias, 2003). Estas alterações no uso do solo são responsáveis por emissões significativas de gases traço e partículas de aerossóis para a atmosfera, através das queimadas, tanto de áreas de pastagem quanto de floresta primária (Artaxo et al., 1998, 2002, 2003), que são objeto de estudo do componente de química atmosférica do LBA-Experimento de Grande Escala da Biosfera e Atmosfera da Amazônia (Artaxo, 2004). Além das emissões de queimadas, a floresta amazônica, por sua localização tropical e seu intenso metabolismo é uma fonte natural importante de gases traço, aerossóis e vapor de água para atmosfera global (Andreae \& Crutzen, 1997). A intensa atividade convectiva lança estes constituintes atmosféricos a grandes altitudes, onde podem ser transportados de modo eficiente a longa distância (Andreae et al., 2001). A região amazônica é uma das fontes principais naturais de compostos orgânicos voláteis para a atmosfera global (Guenther et al., 1995), com significativas emissões de hidrocarbonetos como isopreno e terpenos, além de uma grande variedade de compostos oxigenados. A grande disponibilidade de radiação solar e a grande quantidade de vapor de água na atmosfera são características que favorecem uma alta reatividade química atmosférica na região tropical (Andreae \& Crutzen, 1997). A floresta fornece a maior parte das partículas que atuam como núcleos de condensação de nuvens (NCN), efetivamente controlando os mecanismos de formação de nuvens e precipitação (Artaxo et al., 2003). Recentemente foram compreendidos os processos que ligam as emissões de compostos orgânicos voláteis (VOCs) (Kesselmeir et al., 2000, Wiedinmyer et al., 2004) pela floresta e a concentração de NCN naturais da Amazônia (Clayes et al., 2004, Artaxo et al., 2004, Silva Dias et al., 2004).

As emissões de metano e dióxido de carbono em áreas alagáveis da floresta amazônica é uma parcela importante das emissões destes gases, e é um dos componentes da ciclagem de carbono na floresta, recentemente observada em larga escala na Amazônia. A região tropical, pela alta taxa de radiação solar e de produção de vapor de água, domina a produção global de radicais $\mathrm{OH}$ (hidroxila), que é chamado de "detergente da atmosfera", pois é o principal radical responsável pela oxidação de $\mathrm{CO}$ (monóxido de carbono) e $\mathrm{CH}_{4}$ (metano) em escala global (Andreae \& Crutzen, 1997).

A composição química da atmosfera amazônica sofre grandes mudanças na época da seca, devido às emissões de gases traço e partículas de aerossóis provenientes de queimadas de pastagens e floresta. A intensa atividade de desflorestamento e conseqüente emissão de gases e partículas decorrentes das queimadas durante a estação seca têm implicações importantes em nível local, regional e global (Artaxo et al., 2002). Diversos autores têm mostrado que as emissões de gases traço e partículas de aerossóis pelas queimadas ocorrem de forma significativa e podem afetar o inventário das emissões globais
(Guenther et al., 1995; Andreae et al., 2002; Andreae e Crutzen, 1997, Kaufman et al., 1998). As queimadas são uma significativa fonte global de vários gases de "efeito estufa" como $\mathrm{CO}_{2}$ (dióxido de carbono), $\mathrm{CH}_{4} \mathrm{e} \mathrm{N}_{2} \mathrm{O}$ (óxido nitroso) (Liousse et al., 2004). Também contribuem com emissões significativas de $\mathrm{CO}, \mathrm{NO}_{2}$ (dióxido de nitrogênio), HCNM (Hidrocarbonetos não metano) cloreto e brometo de metila, compostos orgânicos voláteis (VOCs) e dezenas de outros gases (Andreae et al., 2002). De particular importância sobre as características químicas e radiativas são as emissões de precursores de $\mathrm{O}_{3}$, gás formado através de reações fotoquímicas a partir de emissões de queimadas. As emissões de gases precursores da formação de ozônio pelas queimadas faz com que as concentrações deste importante gás atinjam níveis que podem ser danosos à floresta não queimada, a milhares de quilômetros das áreas queimadas, pois o ozônio é fitotóxico, danificando os estômatos das folhas.

O transporte a longa distância de gases traço e partículas de aerossol segue o padrão de circulação atmosférica, fazendo com que as emissões da floresta amazônica saiam do continente Sul Americano por duas vias principais: o Oceano Pacífico tropical e o Oceano Atlântico Sul (Freitas et al., 1997, 2000a, Freitas, 1999). Os movimentos convectivos auxiliam este transporte, fazendo com que em determinadas condições as emissões atinjam inclusive a região do Caribe (Andreae et al., 2001, Okin et al., 2004).

\section{O papel das partículas de aerossóis no balanço de radiação atmosférica na Amazônia}

Entender o papel das partículas de aerossóis emitidas naturalmente pela floresta amazônica na regulação dos mecanismos de produção de nuvens e do balanço radiativo atmosférico tem sido uma tarefa prioritária do componente de química atmosférica do LBA. Diversos experimentos foram realizados em Rondônia ("SMOCC - Smoke, aerosols, clouds, rainfall and climate: Aerosols from biomass burning perturb global and regional climate") e Manaus ("LBA/CLAIRE - Cooperative LBA Airborne Regional Experiment") (Andreae et al., 2002, Artaxo et al., 2002, Guyon et al., 2004, Procópio et al., 2003, 2004). Na estação chuvosa, onde predominam as emissões naturais antrópicas, a concentração de partículas de aerossóis é da ordem de 10 a $15 \mu \mathrm{g} \mathrm{m}^{-3}$, com uma concentração em termos de número da ordem de 100 a 300 partículas $\mathrm{cm}^{-3}$. Na estação seca, por causa das emissões de queimadas, a concentração em massa sobe para cerca de $300 \mathrm{a} 600 \mu \mathrm{g} \mathrm{m}^{-3}$, enquanto que o número de partículas sobe para $15.000 \mathrm{a}$ 30.000 partículas $\mathrm{cm}^{-3}$ (Yamasoe, 1999). A maioria das partículas biogênicas encontra-se na fração grossa, com diâmetros maiores que $2 \mu \mathrm{m}$, e tem como constituição principalmente fungos, esporos, fragmentos de folhas, bactérias, em uma enorme variedade de partículas. A maior parte das partículas são orgânicas, com traços de potássio, cálcio, magnésio, enxofre, fósforo, zinco e outros 


\section{ACTA AMAZONICA}

elementos (Artaxo et al., 1990, 1993, 1994). Elas também são solúveis em água, o que explica suas propriedades de nucleação de nuvens, atuando eficientemente como núcleo de condensação de nuvens (Yamasoe, 2000, Clayes, et al., 2004, Andreae et al., 2004). Estas partículas têm um tamanho da ordem do comprimento de onda da luz visível, o que faz delas eficientes espalhadores de radiação solar, podendo afetar de modo significativo o balanço de radiação atmosférico (Haywood et al., 2000). A Figura 1 apresenta a concentração de partículas de aerossóis em Alta Floresta, norte do estado do Mato Grosso, de 1992 a 2002. Observam-se concentrações muito reduzidas de partículas na estação chuvosa, (da ordem de 10 a $15 \mu \mathrm{g} \mathrm{m}^{-3}$ ) enquanto que no período de agosto a outubro, concentrações altíssimas são observadas (maiores que $100 \mu \mathrm{g} \mathrm{m}^{-3}$ ). Devido às importantes propriedades óticas das partículas emitidas em queimadas (Guyon et al., 2004, 2005), também têm efeitos importantes no balanço de radiação atmosférico, atenuando até $70 \%$ da radiação incidente, afetando o funcionamento do ecossistema amazônico (Eck et al., 2003, Kaufman et al., 1998). Estas altas concentrações de partículas fazem com que haja um déficit de radiação superficial muito significativo, com picos instantâneos de até $-300 \mathrm{Wm}^{-2}$, com valores médios na estação de queimadas em Alta Floresta da ordem de $-28 \mathrm{Wm}^{-2}$ (Procópio et al., 2003, 2004). As altas concentrações também têm efeito importante sobre a saúde da população da região amazônica, com o aumento da incidência de doenças respiratórias em áreas críticas como Alta Floresta (Hacon et al., comunicação pessoal).

O experimento LBA está operando uma rede de fotômetros solares em parceria com a NASA, que mede continuamente a chamada espessura ótica de aerossóis (Holben et al., 1998, Schafer et al., 2002a), que expressa a quantidade total de partículas da coluna atmosférica integrada. A Figura 2 apresenta a série temporal da espessura

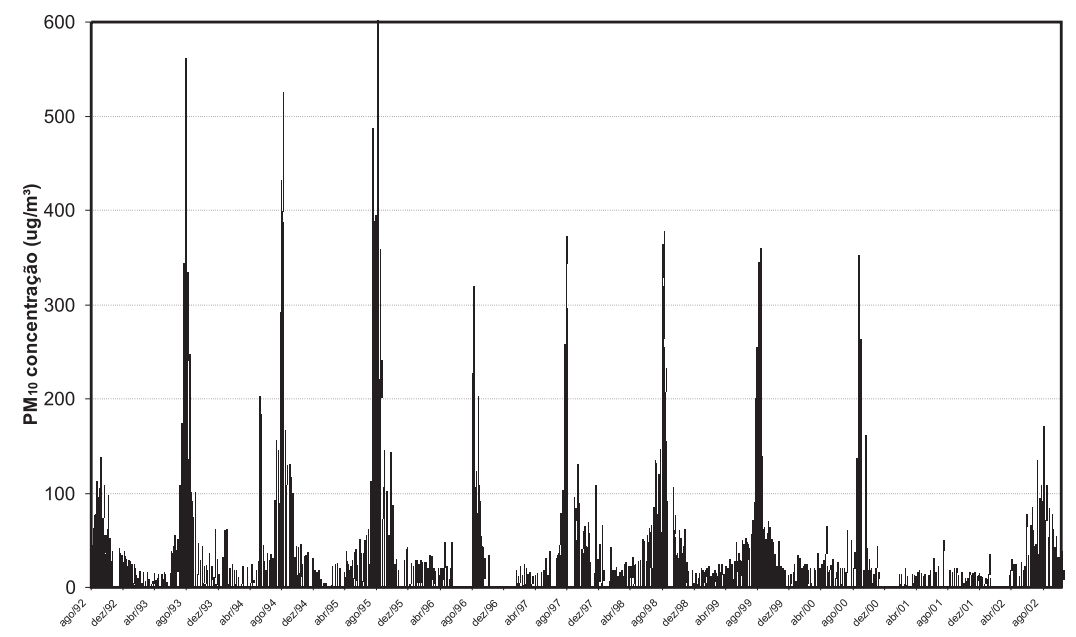

Figura 1 - Concentração de partículas de aerossóis inaláveis em Alta Floresta, norte do estado do Mato Grosso, de Agosto de 1992 a Setembro de 2002. ótica de aerossóis para Rondônia, para o comprimento de onda de 550 nanômetros mostrando um impacto significativo da quantidade de aerossóis no balanço radiativo. A forçante radiativa direta dos aerossóis na superfície foi calculada no espectro solar com o programa de transferência radiativa SBDART - Santa Barbara DISORT Atmospheric Radiative Transfer Model (Ricchiazzi, et al., 1998). Foi desenvolvido um modelo dinâmico de aerossóis para as simulações, onde foi considerada uma superfície coberta por vegetação, uma atmosfera sem nuvens com perfil vertical tropical (do SBDART: vapor d'água $=4.2 \mathrm{~g} \mathrm{~cm}^{-2} \mathrm{e} \mathrm{CO}_{2}=360$ $\mathrm{ppm}$ ). Vários testes de sensibilidade foram feitos baseados em alterações no conteúdo total de vapor de água e na concentração de $\mathrm{CO}_{2}$ na atmosfera (Procópio et al., 2003). O fluxo solar total descendente na superfície (W. $\mathrm{m}^{-2}$ ) foi calculado para 12 valores de profundidade ótica dos aerossóis $(0.10,0.25,0.35,0.45,0.55,0.65,0.75,0.85,0.95$, $1.10,1.40$ e 1.80), e para 16 ângulos solares zenitais variando de $0^{\circ}$ a $86.25^{\circ}$. Assumiu-se uma profundidade ótica dos aerossóis de 'background' de 0.10 para o comprimento de onda de 550 nanômetros $(\mathrm{nm})$, baseado em medidas de climatologia da rede AERONET ao longo de 7 anos de medidas. A forçante radiativa direta dos aerossóis na superfície foi definida como a forçante simulada pelo código de transferência radiativa menos o valor correspondente à situação de background (Procópio et al., 2003).

Para profundidade ótica de 1, por exemplo, a forçante radiativa correspondente pode ser tão alta quanto $-127 \mathrm{Wm}^{-2}$, para um intervalo de ângulo solar zenital de $15-37.5^{\circ}$. Seguindo a mesma linha de raciocínio e assumindo a equação de redução de irradiância dada por Schafer et al. (2002) para um intervalo de ângulo solar zenital de $25-35^{\circ}$, o valor encontrado foi de $-120 \mathrm{Wm}^{-2}$. Para uma espessura ótica de aerossóis da ordem de 2.5 a 3 , a redução do fluxo de radiação na superfície pode ser de $250 \mathrm{Wm}^{-2}$. A redução no fluxo fotossintético (radiação PAR) pode ser da ordem de $70 \%$, afetando fortemente a produtividade primária da floresta amazônica (Eck $e t$ al., 2003, Procópio et al., 2003, 2004). Esta espessa coluna de aerossóis também aumenta a fração de radiação difusa na atmosfera, que por seu lado aumenta a penetração de radiação dentro do dossel da floresta. A vegetação utiliza de modo mais eficiente a radiação difusa para a realização da fotossíntese, fato que balança em parte os efeitos da redução do fluxo direto de radiação. Certamente na maior parte da região amazônica, o efeito da redução do fluxo solar pela absorção das partículas de aerossóis e o aumento da radiação difusa ocorrem durante o período de queimadas (agosto a novembro), e tem efeitos significativos no funcionamento do ecossistema amazônico (Artaxoet al., 2001, 2003). Mas, o impacto em larga escala desta alteração no padrão de radiação ainda tem que ser estudado (Procópio et al., 2004). 


\section{ACTA AMAZONICA}

QUÍMICA ATMOSFÉRICA NA AMAZÔNIA: A FLORESTA E AS EMISSÕES

DE QUEIMADAS CONTROLANDO A COMPOSIÇÃO DA ATMOSFERA AMAZÔNICA

\section{O papel das partículas de aerossóis como núcleos de condensação de nuvens na Amazônia}

As partículas de aerossóis são intimamente ligadas ao ciclo hidrológico porque elas constituem os núcleos de condensação de nuvens, que juntamente com o vapor de água constituem as gotículas de nuvens (Silva Dias et al., 2004, Rosenfeld et al., 2000, Roberts et al., 2001, Andreae et al., 2004). Os NCN são partículas microscópicas de aerossol, que têm propriedades de condensar água em sua superfície (Rizzo et al., 2002). Cerca de 60 a 80\% das partículas naturais de aerossóis na Amazônia atuam como NCN (Zhou et al., 2002, Rissler et al., 2004). Adiferença na concentração de NCN da estação chuvosa para a estação seca (de cerca de 200 para 20.000 partículas $\mathrm{cm}^{-3}$ ) em grandes áreas da Amazônia faz com que as propriedades micro físicas de nuvens sejam profundamente alteradas (Rosenfeld, 1999, 2000, Silva Dias, 2002). Uma veza gota formada, ela começa a crescer através de uma série de mecanismos físicos. Entre o momento em que a gota começa seu processo de crescimento com um diâmetro típico de 20 micrômetros até a sua chegada ao chão, como gota de chuva, com um diâmetro típico de 1 a 2 milímetros, vários processos intermediários podem ocorrer. $\mathrm{O}$ aumento em volume é proporcional ao raio da gota elevado ao cubo e isso corresponde a um aumento de até 1 milhão de vezes a partir do volume inicial. As correntes de ar ascendente dentro de uma nuvem se originam de ar aquecido pelo contato com o chão quente durante o dia. Essas correntes de ar sustentam as gotas de chuva dentro da nuvem enquanto as gotas são pequenas. Mas à medida que essas gotas crescem, torna-se mais difícil sustentá-las e eventualmente elas caem como chuva. As gotas crescem por condensação dovapor d'águae, de forma mais eficiente, pelochoque com outras gotinhas menores que vão se agregando à gota maior e aumentando seu volume. O peso das gotas já formadas e crescentes vai desacelerando o fluxo de ar ascendente. Durante a fase anterior à chuva, as gotas sentem a ação da gravidade puxando-as para baixo mas a bolha quente flutuando contínua levando-as para cima na corrente ascendente, e a nuvem vai crescendo. Nesse momento, ocorre um papel importante da quantidade de aerossóis, e em particular dos NCN. Se o ambienteérelativamentelimpo, nãopoluído, há poucos NCN. Na disputa pelo vapor de água existente, se houver alguns NCN relativamente grandes ou solúveis emágua, estes vão crescer rapidamente, colidir com os menores e cair como chuva. Anuvem não tem muito tempo para crescer chegando no máximo a alturas de 4 ou $5 \mathrm{~km}$.

Caso a atmosfera esteja poluída, com um número muito grande de NCN, como na época de queimadas, a disputa pelo vapor de água disponível aumenta, as gotas crescem pouco e devagar enquanto a nuvem vai crescendo. Muitas vezes essas nuvens nem chegam a chover, as gotas evaporam e a água, junto com os aerossóis, não retorna ao chão mas é levada pelos ventos a outros locais. Se a gota passar dos 6 ou 7 $\mathrm{km}$ de altura, ela congela pois o ar atinge temperaturas muito baixas. As pedrinhas de gelo crescem de forma bastante eficiente enquanto a nuvem cresce até 10 ou $15 \mathrm{~km}$ de altura, formando a chamada nuvem Cumulonimbus. Tipicamente chamamos as nuvens rasas em regiões limpas de nuvens marítimas e as nuvens que contêm gelo, formadas em regiões poluídas, de nuvens continentais. Toda vez que uma nuvem tem grande quantidade de gelo observam-se os relâmpagos e trovões, que podem ser usados justamente para identificar a proximidade de um Cumulonimbus. Na Amazônia, temos chuvas provocadas pelos dois tipos de nuvens, as rasas e as profundas convivendo na época mais limpa do ano que é durante a estação chuvosa. $\mathrm{Na}$ época poluída pela fumaça das queimadas, no entanto, as chuvas de nuvens rasas desaparecem e apenas raras chuvas de nuvens profundas são observadas, com muitos relâmpagos e trovões (Andreae et al., 2004). As chuvas de nuvens rasas na estação chuvosa, por outro lado, devolvem os NCN à superfície praticamente no mesmo lugar em que foram gerados pela floresta. Por esta razão, pesquisadores desenvolveram o conceito de que a Amazônia durante a estação chuvosa, consiste em um "oceano verde", com estrutura de nuvens que não lembram áreas continentais, mas áreas oceânicas (Roberts et al., 2001). As nuvens profundas são carregadas pelos ventos mais fortes de altitude e viajam até centenas de quilômetros para longe de seu local de origem, exportando os NCN dentro das gotas (Silva Dias et al., 2002). Esta supressão de precipitação pode ter impactos importantes no funcionamento do ecossistema Amazônico (Roberts et al., 2002, Artaxo et al., 2002, Rosenfeld, 1999, 2000).

Outro aspecto importante na estrutura de nuvens durante a estação seca, com forte impacto de queimadas, é a presença significativa de partículas que absorvem radiação, o chamado "black carbon", que consiste em fuligem das queimadas (Martins et al., 1998). Gotículas de nuvens ricas em fuligem absorvem radiação muito eficientemente, evaporando-se antes de precipitarem, intensificando a supressão da precipitação. Com

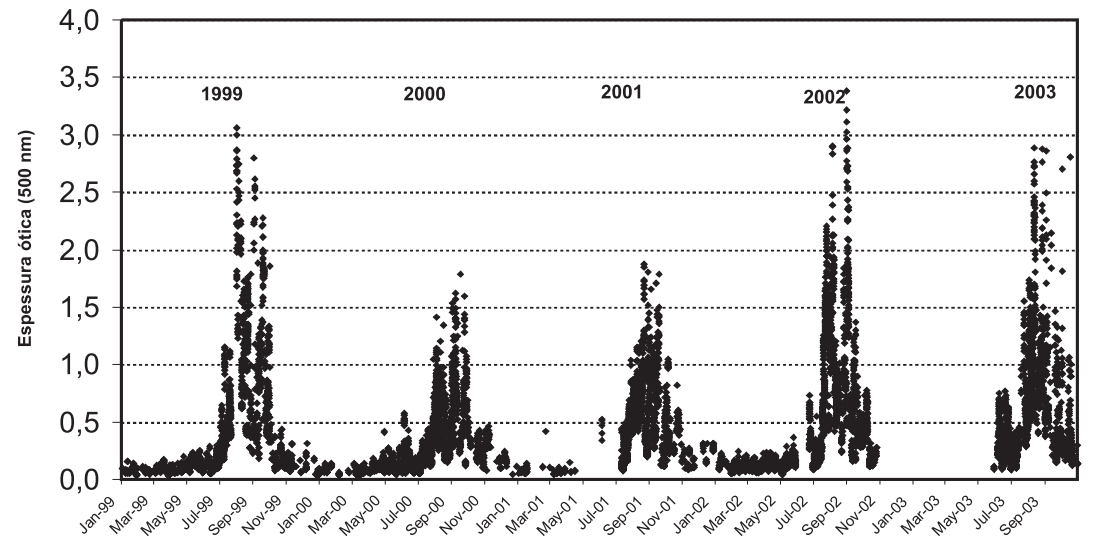

Figura 2 - Espessura ótica de aerossóis em Ji-Paraná (Rondônia), para o período de 1999 a 2003, para o comprimento de onda de 550 nanômetros, obtida com o fotômetro solar da rede NASA/AERONET em operação no LBA. 


\section{ACTA AMAZONICA}

as altas concentrações de black carbon durante a estação seca (de $5 \mathrm{a} 40 \mu \mathrm{g} \mathrm{m}^{-3}$ ), este fenômeno é particularmente importante na Amazônia, comparada com outras regiões do globo.

\section{O papel das partículas de aerossóis na ciclagem de nutrientes na Amazônia}

As partículas de aerossóis transportam nutrientes essenciais para a floresta amazônica, e fazem parte do eficiente mecanismo de ciclagem de nutrientes da floresta (Artaxo \& Hansson, 1995, Artaxo et al., 1988, Okin et al., 2004). Os processos de deposição úmida (através da chuva) e seca (através das partículas de aerossóis) mantêm um fluxo interno de nutrientes na Bacia Amazônica que é altamente desenvolvido (Lara et al., 2001). Existem algumas evidências de que a produtividade primária de florestas tropicais pode estar sendo limitada pela quantidade de fósforo, sendo possível que florestas tropicais não cresçam proporcionalmente ao aumento de dióxido de carbono atmosférico devido à forte limitação da quantidade de fósforo disponível. A natureza da mineralização de fósforo em solos é um fator que controla a sua disponibilidade ao ecossistema. A entrada atmosférica de fósforo em florestas tropicais pode ser uma fonte importante em regiões com solos de fertilidade pobre (Okin et al., 2004). Esta entrada ocorre por deposição atmosférica seca e úmida, sendo a primeira em fase de aerossóis e a segunda como chuva. Nosso conhecimento é bastante limitado sobre os mecanismos de entrada de fósforo através de aerossóis no ecossistema amazônico, pois este elemento é reciclado no ecossistema local através de partículas de aerossóis biogênicos. A entrada oceânica de fósforo é muito limitada na Amazônia, pois este elemento aparece em concentrações extremamente baixas no Atlântico tropical. A entrada de aerossóis contendo fósforo provenientes do deserto do Saara pode ser importante em escalas longas de tempo, mas pouco relevante em algumas dezenas de anos.

A concentração de fósforo na água de chuva amazônica é extremamente baixa, na faixa de partes por bilhão ou menos (Lacaux \& Artaxo, 2003). Mas, nas partículas de aerossóis, a concentração de fósforo apresenta aspectos muito peculiares. As concentrações de fósforo são significativas somente para a fração grossa do aerossol, e estas partículas são emitidas majoritariamente durante a noite (Artaxo et al., 2001). A fração grossa do aerossol tem uma meia vida atmosférica muito curta, depositando-se rapidamente perto do local onde ocorreu a emissão. Durante o período noturno, a atmosfera tem características estáveis, o que suprime a convecção que poderia levar estas partículas para longe de onde foram emitidas. $\mathrm{O}$ conjunto destas duas características faz com que fósforo seja reciclado localmente, minimizando a possibilidade de perda regional deste importante nutriente. Não se conhece as razões ou os mecanismos peculiares de emissão de fósforo no período noturno e na fração grossa, mas este comportamento é importante para minimizar as perdas deste nutriente chave (Artaxo et al., 2002). A Figura 3 apresenta as concentrações de fósforo medidas na torre da Reserva Ecológica do Rio Jaru (Rebio Jaru), em Rondônia, para os períodos diurno e noturno, e para as frações fina e grossa do aerossol (Artaxo et al., 2002). Observa-se nesta figura a forte presença de fósforo durante 0 período noturno e rente ao solo. Durante o dia e na parte

Tabela 1 - Resultados de análise de fatores principais para a composição de aerossóis na estação chuvosa na Amazônia. Em geral obtemos 3 fatores, sendo um deles associado com partículas de aerossóis do solo, um segundo com a componente fina de aerossóis biogênicos e um terceiro com a componente grossa de aerossóis biogênicos. O fósforo sempre aparece quase que exclusivamente nesta terceira componente de aerossóis biogênicos da fração grossa do aerossol.

\begin{tabular}{lcccc}
\hline \hline Elemento & Fator 1 & Fator 2 & Fator 3 & Comun. \\
\hline $\mathrm{Al}$ & Partículas do solo & $\begin{array}{c}\text { Aerossóis biogênicos } \\
\text { finos:S, Zn, Sr }\end{array}$ & $\begin{array}{c}\text { Aerossóis biogênicos } \\
\text { grossos:P, K, Cl, Sr }\end{array}$ & $(\mathbf{1})$ \\
$\mathrm{Si}$ & 0.97 & $(0.06)$ & $(0.14)$ & 0.97 \\
$\mathrm{P}$ & 0.97 & $(0.05)$ & $(0.15)$ & 0.97 \\
$\mathrm{~S}$ & $(0.13)$ & $(0.13)$ & 0.97 & 0.97 \\
$\mathrm{Cl}$ & $(0.09)$ & 0.91 & $(0.11)$ & 0.84 \\
$\mathrm{~K}$ & 0.71 & $(0.01)$ & 0.34 & 0.62 \\
$\mathrm{Ca}$ & 0.57 & 0.29 & 0.74 & 0.95 \\
$\mathrm{Ti}$ & $(0.18)$ & $(0.21)$ & 0.88 \\
$\mathrm{Mn}$ & 0.90 & $(0.18)$ & $(0.15)$ & 0.99 \\
$\mathrm{Fe}$ & $(0.16)$ & $(0.15)$ & 0.98 \\
$\mathrm{Zn}$ & 0.97 & $(0.05)$ & $(0.14)$ & 0.99 \\
$\mathrm{Sr}$ & 0.96 & 0.88 & $(0.11)$ & 0.79 \\
\hline Porc. Var. (2) & 0.98 & 0.52 & 0.39 & 0.83 \\
\hline \hline
\end{tabular}

(1) Expressa a comunalidade de cada variável na análise de fatores principais, que indica a fração da variabilidade de cada elemento explicada pelo modelo. (2) A linha "Porc. Var." expressa a porcentagem da variabilidade total explicada por cada um fatores retidos. 


\section{ACTA \\ AMAZONICA}

QUÍMICA ATMOSFÉRICA NA AMAZÔNIA: A FLORESTA E AS EMISSÕES

DE QUEIMADAS CONTROLANDO A COMPOSIÇÃO DA ATMOSFERA AMAZÔNICA superior das copas das árvores, a concentração de fósforo é baixa, pois emissões de aerossóis neste período de máxima convecção atmosférica certamente fariam o ecossistema local perder uma fração importante deste nutriente crítico.

Quando realizamos a análise elementar de partículas de aerossóis na Amazônia durante a estação chuvosa, um mesmo quadro emerge para várias localizações da Amazônia. A análise de fatores principais, que identifica padrões de similaridade na composição elementar de amostras coletadas, é uma ótima ferramenta para estudar a composição de aerossóis (Artaxo et al., 2002). Em geral obtemos 3 fatores principais, sendo um deles associado com partículas de aerossóis do solo, um segundo com a componente fina de aerossóis biogênicos e um terceiro com a componente grossa de aerossóis biogênicos. A componente fina dos aerossóis está associada ou às emissões de queimadas na estação seca, ou a partículas produzidas a partir de gases biogênicos precursores de partículas (Andreae \& Crutzen 1997, Schkolnik et al., 2005). A componente de partículas biogênicas na fração grossa do material particulado tem origem natural, são emitidas diretamente pelas plantas e estas partículas são excelentes núcleos de condensação de nuvens pelo seu tamanho (da ordem de 10 a 20 micrômetros). O fósforo sempre aparece nesta terceira componente biogênica natural. A Tabela 1 apresenta resultados de análise de fatores principais para a composição de aerossóis na estação chuvosa em Rondônia, em amostras coletadas em 1999 durante o experimento LBA/ CLAIRE, ilustrando o quadro discutido acima.

\section{As altas concentrações de ozônio decor- rente das queimadas}

Na estação chuvosa, concentrações relativamente baixas de $\mathrm{CO}, \mathrm{O}_{3}$, NOx e outros gases resultam das emissões biogênicas naturais da floresta (Jacob \& Wofsy, 1988) e da atividade fotoquímica nesta região tropical. Durante a estação de queimadas, a composição atmosférica do ponto de vista de gases traço muda significativamente, alterando profundamente os mecanismos que regulam a composição atmosférica (Longo et al., 1999). A concentração de ozônio ao meio do dia típica da estação chuvosa é de cerca de 10 a $15 \mathrm{ppb}$, enquanto altos valores da ordem de 50 a $100 \mathrm{ppb}$ são observados durante a estação de queimadas (Cordova et al., 2004). As concentrações de monóxido de carbono (CO) em Rondônia durante a estação chuvosa variam de 100 a 150 ppb, enquanto que na estação de queimadas variam de 1.000 a 8.000 ppb (Cordova, 2003, Artaxo et al., 2002). As concentrações de óxidos de nitrogênio (NOx) naturais na Amazônia, da ordem de 0.8 ppb na estação chuvosa atingem valores de 4 a 16 ppb durante a estação de queimadas em Rondônia. Estas altas concentrações correspondem a valores tipicamente observados no centro da cidade de São Paulo durante os episódios críticos de poluição de ar urbana no período de inverno, (CETESB, 2003) e abrangem uma área geográfica muito extensa na Amazônia. As concentrações de aerossóis na Amazônia durante a estação seca também são muito mais elevadas que as concentrações observadas em São Paulo (Castanho et al., 2001. Landulfo et al., 2003).

Medidas utilizando a aeronave Bandeirante do INPE em agosto e setembro de 2002, durante o experimento LBA/ SMOCC (Smoke Aerosols, Clouds, Rainfall and Climate: Aerosols from Biomass Burning Perturb Global and Regional Climate) realizado em 2002 em Rondônia e Acre indicam um eficiente transporte de gases precursores de ozônio, que fazem com que as concentrações deste gás apresentem valores muito altos em regiões longe da ocorrência de queimadas (Cordova, 2003). Foram observadas concentrações elevadas de ozônio na região de Cruzeiro do Sul, e simulações realizadas com o modelo RAMS acoplado a mecanismos químicos indicam que estas altas concentrações de ozônio ocorreram pelo transporte a longa distância de gases precursores, provenientes de Mato Grosso e Rondônia.

Um aspecto importante e muito particular da concentração de ozônio em algumas áreas da Amazônia é o fato de que foram observados eventos freqüentes de aumento da concentração de ozônio durante o período noturno (Cordova et al., 2004). Este aumento se dá pelo transporte vertical de massas de ar descendentes, provenientes da média troposfera, mais ricas em ozônio, que também possuem menor conteúdo de umidade específica. Sistemas convectivos noturnos freqüentemente trazem massas de ar da média troposfera para o nível do solo. Este transporte vertical de $\mathrm{O}_{3}$ foi observado em três locais estudados, em áreas de pastagem (Fazenda Nossa Senhora em Rondônia) e florestas (Balbina e FLONA-Tapajós) durante as estações chuvosa, de transição e seca. A maior freqüência, entretanto, foi observada na região da Floresta Nacional de Tapajós (observado em $65 \%$ dos períodos noturnos estudados). O aumento da concentração de ozônio noturno apresentou correlação negativa com a temperatura potencial equivalente, indicando que houve transporte de massas de ar mais frias e secas da média troposfera, enriquecidas em $\mathrm{O}_{3}$.

Durante o experimento LBA/CLAIRE 2001 foi observado, em Balbina, um aumento das concentrações de aerossóis e $\mathrm{NO}_{2}$ associado a massas de ar de origem polar que atingiu a

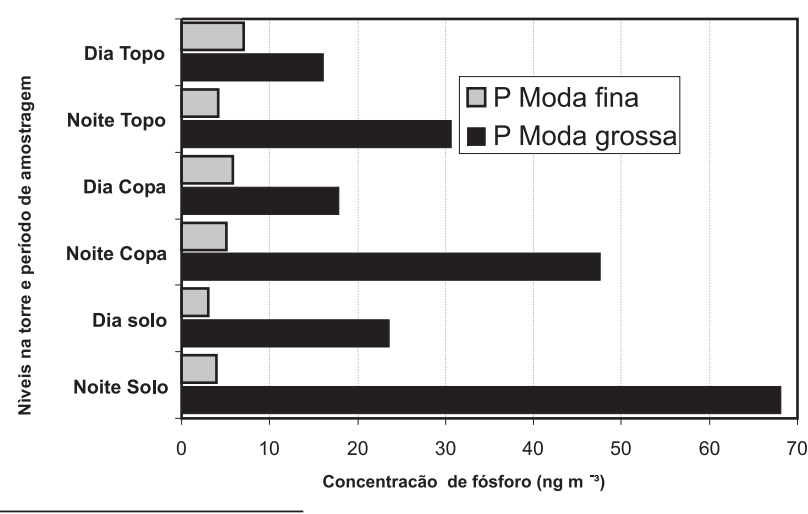

Figura 3 - Concentrações de fósforo medidas na torre da reserva Ecológica do Rio Jaru (Rebio Jaru), em Rondônia, para os períodos diurno e noturno, e para as frações fina e grossa do aerossol. 


\section{ACTA \\ AMAZONICA}

QUÍMICA ATMOSFÉRICA NA AMAZÔNIA: A FLORESTA E AS EMISSÕES

DE QUEIMADAS CONTROLANDO A COMPOSIÇÃO DA ATMOSFERA AMAZÔNICA

região amazônica, após passar pelo sul do país. Simulações numéricas realizadas com o modelo RAMS mostraram que houve transporte de aerossóis e $\mathrm{NO}_{\mathrm{x}}$ emitidos por queimadas, em Mato Grosso, transportados pelas massas de ar frio até a região de Balbina. Este estudo mostrou como o transporte de longa distância pode modificar a composição química da atmosfera de regiões de florestas preservadas. Medidas realizadas com o avião Bandeirante do INPE em Rondônia, durante o experimento SMOCC, mostra que em condições de ausência de queimadas $\mathrm{o}_{3}$ apresenta um perfil característico de áreas não perturbadas com um aumento da concentração com a altura, alcançando valores de 50 ppb a $4.000 \mathrm{~m}$ de altura, similares às concentrações medidas na Rebio Jaru. $\mathrm{O}$ perfil vertical de $\mathrm{O}_{3}$ indica, em geral, concentrações mais baixas a altitudes menores que 1.000 metros, causada pela deposição sobre a floresta em regiões mais preservadas como ao sul do Estado do Amazonas.

\section{O modelamento do transporte a longa distância de gases e partículas}

A atmosfera é um sistema aberto, não isolado, e como tal a composição em termos de aerossóis e gases traçoé influenciada não só pelas emissões locais, mas também pelo transporte a longa distância. Em particular na Amazônia, movimentos convectivos freqüentes influenciam significativamente o transporte de gases e partículas de aerossóis (Freitas, 1999, Freitas et al., 2003). Para o estudo do transporte de gases traço e aerossóis na Amazônia, foi desenvolvido o modelo 'Coupled Aerosol and Tracers Transport model to the Brazilian Regional Atmospheric Modeling System' (CATT-BRAMS) (Freitas et al., 2003). O sistema consiste em um modelo numérico de transporte de aerossóis e traçadores atmosféricos acoplado à versão brasileira do modelo RAMS (Walko et al., 2000). O RAMS é um modelo numérico em diferenças finitas desenvolvido para simular os movimentos da atmosfera em várias escalas, possuindo um elaborado conjunto de parametrizações físicas para simular os processos governantes da evolução do estado atmosférico. A condição inicial pode ser definida a partir de vários conjuntos de dados observacionais e, como condição de contorno, o modelo tem o esquema 4DDA (assimilação de dados em 4 dimensões) o qual permite que a solução do sistema de equações seja confidente com dados analisados de escala maior, tais como análises atmosféricas de modelos globais. O BRAMS é derivado da mais recente versão do modelo RAMS (5.0) com várias inovações, tais como novo módulo de parametrização de umidade do solo, nova parametrização de cumulus rasos e profundos baseada no formalismo de fluxo de massa e com uma técnica de 'ensembles' para determinação do fluxo de massa (Grell \& Devenyi, 2002). O CATT-BRAMS é um modelo 3D Euleriano que prognostica a concentração de contaminantes atmosféricos de forma simultânea e totalmente consistente com o estado atmosférico simulado pelo RAMS/ BRAMS. Este procedimento rivaliza com a forma tradicional dos modelos de química da atmosfera, nos quais o transporte é feito 'off-line' usando os dados atmosféricos (dinâmicos e termodinâmicos) gerados previamente e salvos em discos. As principais vantagens deste procedimento se devem ao fato de permitir ter o prognóstico simultâneo do estado atmosférico dos pontos de vista meteorológico e de qualidade do ar (útil em situações de previsão de qualidade do ar, veja www.cptec.inpe.br/meio_ambiente) e permitir o estudo da interação ou da retro-alimentação entre o contaminante e a própria atmosfera (como no caso de aerossóis de queimadas e sua forçante radiativa).

Do ponto de vista termodinâmico, o acoplamento on-line com o modelo de aerossóis CARMA "Community Aerosol \& Radiation Model for Atmospheres" é essencial para estudar as modificações na estrutura termodinâmica da atmosfera devido a presença das partículas de aerossol de fumaça. As partículas de aerossol de queimadas espalham e absorvem radiação solar eficientemente e, portanto, atenuam a radiação solar ao nível da superfície. As diferenças de temperaturas associadas com a presença das partículas de aerossol de fumaça podem chegar a $2^{\circ} \mathrm{C}$, com redução próximo à superfície e aumento na metade superior da camada limite planetária. Consequentemente, o modelo responde com uma redução na energia cinética turbulenta, nos níveis próximos da superfície associada à presença dos aerossóis. Essa redução está associada à quantidade de radiação solar que chega na superfície para aquecê-la e gerar a turbulência que é transmitida para os níveis atmosféricos adjacentes a superfície e promover movimento ascendente.

Comparação com observações locais de espessura ótica do aerossol (AOT) da rede AERONET com o material particulado verticalmente integrado na coluna do modelo apontam para comparações bastante favoráveis, indicando que os processos de emissão e transporte são adequadamente representados no modelo. As comparações entre os valores modelados e as observações de superfície em Rondônia também indicam uma excelente performance do modelo.

Desde junho de 2003 o sistema de monitoramento de CO e $\mathrm{PM}_{2.5}$ tem sido executado operacionalmente, no CPTEC/ INPE (www.cptec.inpe.br/meio_ambiente). O monitoramento se beneficia também das informações de focos de queimadas obtidas por vários sensores de focos de queimadas tais como: MODIS (operacional nos satélites Terra e Aqua), AVHRR (NOAA 12 e 16) e GOES-12 processados pelo INPE. Foi estabelecido um algoritmo de filtragem para eliminar focos coincidentes entre si e com o produto já utilizado (WF_ABBA do GOES-12). O produto final utilizado para assimilação de focos de queimadas no modelo de transporte, obtido por multidetecção, possui qualidade superior ao utilizado em 2002.

\section{Deposição atmosférica e ciclagem de nutrientes}

Para se entender o funcionamento de ecossistemas tropicais é essencial se compreender os principais aspectos da deposição química atmosférica. A deposição atmosférica, úmida e seca, participa nos processos de controle de concentração de gases e aerossóis na troposfera e no aporte de nutrientes para ecossistemas aquáticos e ou terrestres (Chadwick et al., 
1999, Artaxo et al., 2001), além de integrar vários mecanismos físicos e químicos como processos de emissão e remoção, dinâmica de transferência na atmosfera e reações químicas. Estudos de deposição atmosférica fornecem, portanto, informações sobre a variabilidade espacial e temporal da composição química atmosférica, além de ser um forte indicador de influências antrópicas ou de origem natural.

Frequentemente, a variabilidade espacial e temporal da deposição de um determinado composto depende do tempo de residência de gases e aerossóis na atmosfera, os quais são determinados pela sua reatividade química. Em ambientes tropicais, principalmente durante a época chuvosa, eventos convectivos produzem grandes quantidades de precipitação que são a principal fonte de remoção de gases e partículas da atmosfera. Ainda, em regiões onde os ciclos biogeoquímicos estão sendo perturbados por ações antrópicas, como é o caso de algumas áreas na Amazônia (Gash et al., 1996; Neill et al., 2001), a deposição atmosférica pode ser uma importante fonte de remoção de poluentes assim como um significante aporte de nutrientes para o ecossistema. Além do que, a deposição atmosférica nos trópicos é particularmente peculiar devido às suas características únicas, como o grande fluxo de radiação ultra-violeta, altas temperaturas e vapor d'água, que promovem intensa atividade fotoquímica durante todo o ano.

Neste contexto se destaca a região amazônica, um ecossistema tropical único que ainda preserva grande parte de sua floresta nativa mas que, no entanto, vem sofrendo extensivas mudanças no uso do solo, principalmente ao longo da fronteira com outros Estados do Brasil (Gash et al., 1996; Artaxo et al., 2001). A última estimativa de desmatamento na região amazônica, para 2003 totalizou aproximadamente 23.800 $\mathrm{km}^{2}$ por ano de área desmatada (www.obt.inpe.br/prodes). Essas rápidas trocas no uso do solo contribuem para alterações nos fluxos de carbono e nitrogênio, gases-traço, fertilidade do solo, além de mudanças nos ciclos biogeoquímicos terrestres e atmosféricos, com impactos no clima regional e, possivelmente global (Artaxo et al., 2002; Neill et al., 2001; Silva Dias et al, 2002).

Estudos recentes realizados em duas áreas da bacia amazônica; Balbina, cujo principal uso do solo é a cobertura vegetal nativa e em Rondônia, onde o desmatamento já chegou a atingir 25\% da área total do Estado (www.inpe.br) mostraram que a composição química e a deposição atmosférica estão sendo alteradas pelas mudanças no uso do solo (Artaxo et al., 2002; Artaxo et al., 2003). Por exemplo, a concentração de DOC (dissolved organic carbon) na água de chuva, somente durante o período seco, em Rondônia (VWM DOC = $182 \mathrm{uM}$ / L) foi superior à concentração anual em Lago Calado (VWM DOC $=154 \mathrm{uM} / \mathrm{L})$ (Williams et al., 1997) e a de regiões industrializadas do Estado de São Paulo, onde também ocorre queima de biomassa durante o período seco (concentração média em VWM DOC = $100 \mathrm{uM} / \mathrm{L}$ ) (Lara et al., 2001). Essa alta concentração de DOC pode estar associada à extensa área de solo exposto em Rondônia, assim como ao grande número de focos de queimadas no Estado. Em água de chuva, DOC pode ser um dos principais componentes do material dissolvido, tanto de origem biogênica como antrópica (Andrea et al., 1990; Lara et al., 2001), além de ser um potencial reagente em algumas reações atmosféricas, como processos fotoquímicos e complexação de metais traço (Willey et al., 2000). Estudos de remoção de carbono da atmosfera via DOC e DIC (dissolved inorganic carbon) são essenciais para um entendimento dos fluxos de carbono que ocorrem entre a atmosfera e biosfera e, consequentemente uma melhor compreensão do ciclo do carbono. Apesar disso, poucos são os trabalhos que relatam informações sobre deposição de DOC e DIC (Williams et al., 1997; Willey et al., 2000; Lara et al., 2001).

Ácidos orgânicos, como acético, fórmico, oxálico, pirúvico, metanosulfônico são os maiores constituintes do DOC em água de chuva e, podem contribuir para o aumento da acidez da precipitação tanto em áreas remotas como em regiões com interferência antrópica (Keene \& Galloway, 1984; Avery et al., 2001). As concentrações, deposição e percentual de contribuição para a acidez da precipitação dos ácidos orgânicos variam de acordo com as condições atmosféricas, potencial de oxidação, e fontes emissoras. Estudos prévios realizados em Balbina e Rondônia sugerem que emissões diretas são a principal fonte de ácidos orgânicos, principalmente acético e fórmico. No entanto, quando se analisa a variabilidade sazonal de acetato e formato, algumas importantes diferenças emergem entre as estações seca e chuvosa. Acréscimo nas concentrações e na razão F/A (formato/acetato) durante o período seco em Rondônia e Balbina indicam outras possíveis fontes de formato, que podem estar associadas à formação fotoquímica de ácido fórmico na atmosfera, devido às altas temperaturas e radiação solar (Hartmann et al., 1991). Ainda, emissões de queimadas também podem estar alterando a concentração dos ácidos orgânicos na região, principalmente em Rondônia, uma vez que emissões diretas de queima de biomassa são conhecidas fontes de ácidos carboxílicos de baixo peso molecular e alta polaridade (Falkovich et al., 2005, Sanhueza et al., 1996; Kawamura et al., 1996). Aumento nas concentrações de ácidos orgânicos podem levar a um acréscimo na acidez da precipitação, com graves conseqüências para os ecossistemas. Considerando que a maioria dos solos tropicais são altamente intemperizados, relativamente pobres em nutrientes e, consequentemente, podem ser afetados pela deposição ácida (Cerri et al., 2001; Krusche et al., 2003), é necessário um melhor conhecimento sobre a acidez e composição da precipitação e dos aerossóis sobre a Amazônia e dos efeitos destes contaminantes neste ecossistema tropical (Trebbs et al., 2005a, 2005b).

Outra importante conseqüência do desmatamento na Amazônia se evidencia no ciclo biogeoquímico do nitrogênio. A conversão de floresta primária para plantações ou pastagem tem induzido a um declínio da produtividade do solo acompanhado de mudanças nos fluxos de gases traços como, por exemplo, óxidos de nitrogênio, acarretando mudanças no ciclo do N no solo (Neill et al., 2001). Por exemplo, solos de pastagens em Rondônia já não são mais limitados por $\mathrm{P}$, como acontece nos rios de floresta, mas sim por N (Neill et al., 2001). Ao mesmo tempo, as constantes mudanças no uso do 


\section{ACTA \\ AMAZONICA}

solo estão, também, alterando o padrão de deposição de $\mathrm{N}$. Em Rondônia a deposição de N (5.7 kg.N.ha $\left.{ }^{-1} \cdot \mathrm{yr}^{-1}\right)$ é, praticamente, o dobro do que em regiões mais preservadas da Amazônia (2.9 kg.N.ha-1. $\mathrm{yr}^{-1}$ ) e da mesma magnitude da deposição úmida em áreas com forte influência antrópica do Estado de São Paulo (5.6 kg.N.ha-1 ${ }^{-1} \mathbf{r r}^{-1}$ ) (Lara et al., 2001; 2005). Tanto óxidos de nitrogênio, como amônia são emitidos por processos biológicos no solo e durante as queimadas (Delmas et al., 1995; Lara et al., 2001; Trebbs et al., 2005b, Neff et al., 2001). Estudos realizados durante a campanha SMOCC - 2002, em Rondônia, mostraram como as emissões de queimada interferem na composição e deposição de N (Lara et al., 2005). Há uma correlação positiva $(\mathrm{P}<0.01)$ entre a deposição de N$\mathrm{NO}_{3} \cdot(\mathrm{r}=0.97), \mathrm{N}^{-\mathrm{NH}_{4}}{ }^{+}(\mathrm{r}=0.99)$ e o número de focos de queimada no Estado de Rondônia, o que mostra claramente que as emissões de queimada estão alterando o padrão de deposição de $\mathrm{N}$ na região de Rondônia. Emissões de queimada, urbanização e industrialização não só estão aumentando a deposição de $\mathrm{N}$ em regiões impactadas do Brasil mas, principalmente, mudando a composição da deposição de N, de $\mathrm{NO}_{3}^{-}$para $\mathrm{NH}_{4}^{+}$. Enquanto que $\mathrm{NO}_{3}$-é a forma predominante na deposição de $\mathrm{N}$ em áreas mais preservadas do Estado de São Paulo e da Amazônia, a deposição de $\mathrm{N}_{-} \mathrm{NH}_{4}^{+}$chega a corresponder a até $65 \%$ do total de $\mathrm{N}$ depositado em áreas impactadas (Lara et al., 2005, Trebbs et al., 2005b). Como a deposição de $\mathrm{N}$ está mudando de uma forma oxidada para outra reduzida, importantes alterações podem ocorrer na química atmosférica e nos ecossistemas aquáticos e terrestres (Krusche et al., 2003). O ciclo do $\mathrm{N}$ em ambientes tropicais é diferente de regiões temperadas (Martinelli et al, 1999). A principal diferença é que os ecossistemas tropicais são mais limitados em $P$ do que em N. Consequentemente, a deposição de $\mathrm{N}$ provavelmente não afetará a produtividade primária, porém, as conseqüências do aumento na deposição de nitrogênio em ambientes tropicais, com um ciclo muito mais rápido ainda são incertos.

\section{CONCLUSÕES}

A composição e a estrutura da atmosfera amazônica está sofrendo mudanças significativas devido a alterações no uso de solo em algumas áreas da Amazônia. Alterações importantes na concentração de partículas de aerossóis e na concentração de vários gases traço ocorrem como decorrência das emissões de queimadas. Estas alterações ocorrem desde a escala local até milhares de quilômetros longe das regiões de emissões. $\mathrm{O}$ ciclo hidrológico pode estar se alterando devido à emissão de grandes quantidades de partículas que atuam como núcleos de condensação de nuvens, e propriedades microfísicas de nuvens estão sendo alteradas. Possivelmente estas alterações na microfísica de nuvens pode estar alterando o padrão de precipitação na região. A ocorrência de nuvens altas, e a supressão da formação de nuvens rasas está ocorrendo em algumas áreas. As mudanças de uso de solo também está afetando as emissões de gases biogênicos que participam dos processos de formação de partículas e nuvens. Fortes alterações no balanço radiativo atmosférico podem estar afetando a assimilação de carbono pelo ecossistema, com alterações na produtividade primária da floresta em largas áreas.

O conjunto destas fortes alterações em processos atmosféricos críticos para a saúde do ecossistema indicam que mudanças de uso de solo vão além somente da troca de floresta por áreas de pastagem e cultivo, mas apontam para mudanças ambientais mais profundas com efeitos no ecossistema amazônico e possivelmente no clima de outras regióes do Brasil.

\section{AGRADECIMENTOS}

Agradecemos o apoio da FAPESP e do CNPq/PADCT pelo suporte ao Instituto do Milênio do Experimento LBA. Agradecemos a M. O. Andreae, Alex Guenther, Daniel Rosenfeld, Brent Holben, Steven Wofsy, Bill Munger e um número grande de pesquisadores brasileiros e estrangeiros atuantes no LBA, que estão contribuindo para o entendimento dos processos críticos que regulam a composição da atmosfera Amazônica e seus efeitos no ecossistema.

\section{BIBLIOGRAFIA CITADA}

Andreae, M. O.; Crutzen, P. J. 1997. Atmospheric aerosols: biogeochemical sources and role in atmospheric chemistry. Science, 276: 1.052-1.058.

Andreae, M.O.; Artaxo, P.; Fischer, H.; Freitas, S. R. 2001. Transport of biomass burning smoke to the upper troposphere by deep convection in the equatorial region. Geophysical Research Letters, 28 (6): 951-954.

Andreae, M.O.; Almeida, S. S. de; Artaxo, P.; Brandão, C.; Carswell, F. E.; Ciccioli, P.; Culf, A.; Esteves, J. L.; Gash, J.; Grace, J.; Kabat, P.; Lelieveld, J.; Malhi, Y.; Manzi, A. O.; Meixner, F. X.; Nobre, A.; Nobre, C.; Ruivo, M. A. de L.; Silva-Dias, M. A. F.; Stefani, P.; Valentini, R.; Jouanne, J. von; Waterloo, M. 2002. Biogeochemical cycling of carbon, water, energy, trace gases and aerosols in Amazonia: The LBA-EUSTACH experiments. Journal of Geophysical Research, 107 (D20): 8.066 - 8.091, doi:10.1029/2001JD000524.

Andreae, M.O.; Rosenfeld, D.; P. Artaxo, P.; Costa, A. A.; Frank, G. P.; Longo, K. M.; Silva Dias, M. A. F. 2004. Smoking rain clouds over the Amazon. Science, 303: 1342-1345.

Artaxo, P.; Storms, H.; Bruynseels, F.; Van Grieken, R.; Maenhaut, W. 1988, Composition and sources of aerosols from the Amazon Basin. Journal of Geophysical Research, 93: 1.605 - 1.615.

Artaxo, P.; Maenhaut, W.; Storms, H.; Van Grieken, R. 1990, Aerosol characteristics and sources for the Amazon basin during the wet season. Journal of Geophysical Research, 95 (D10): 16.971-16.985.

Artaxo, P.; Yamasoe, M.; Martins, J. V.; Kocinas, S.; Carvalho, S.; Maenhaut, W. 1993. Case study of atmospheric measurements in Brazil: Aerosol emissions from Amazon Basin Biomass Burning. In: Crutzen, P.J.; Goldammer J.-G. (Eds.). Fire in the Environment: The ecological, atmospheric, and climatic importance of vegetation fires. Dahlem Konferenzen ES13, John Wiley \& Sons, NY. 139-158. 
Artaxo, P.; Gerab, F.; Yamasoe, M.A.; Martins, J.V.;1994. Fine Mode Aerosol Composition in Three Long Term Atmospheric Monitoring Sampling Stations in the Amazon Basin. Journal of Geophysical Research, 99 (D11): 22.857-22.868.

Artaxo, P.; Hansson, H-C; 1995. Size distribution of biogenic aerosol particles from the Amazon basin. Atmospheric Environment, 29(3): 393-402.

Artaxo, P.; Fernandes, E. T.; Martins, J. V.; Yamasoe, M. A.; Hobbs, P. V.; Maenhaut, W.; Longo, K. M.; Castanho, A.; 1998. Large Scale Aerosol Source Apportionment in Amazonia. Journal of Geophysical Research, 103 (D24): 31.837-31.848.

Artaxo, P.; Andreae, M. O.; Guenther, A.; Rosenfeld, D.; 2001. LBA Atmospheric Chemistry: Unveiling the lively interactions between the biosphere and the Amazonian atmosphere. In: IGBP Global Change Newsletter, LBA Special Issue, 12-15.

Artaxo, P.; 2001b. The atmospheric component of biogeochemical cycles in the Amazon basin, In: McClain, M. E.; Victória, R. L.; Richey, J.E (Eds). The biogeochemistry of the Amazon basin.; Oxford University Press, Oxford. p 42-52.

Artaxo, P.; Martins, J. V.; Yamasoe, M. A.; Procópio, A. S.; Pauliquevis, T. M.; Andreae, M. O.; Guyon, P.; Gatti, L. V.; Cordova, A. M. 2002. Physical and chemical properties of aerosols in the wet and dry season in Rondônia, Amazonia. Journal of Geophysical Research, 107 (D20) 8.081-8.095, doi:10.1029/2001JD000666.

Artaxo, P.; Silva Dias, M. A. F.; 2003. Nuvens de fumaça das queimadas alteram o clima da Floresta Amazônica. Revista FAPESP, 88: 30-25.

Artaxo, P.; Silva-Dias, M. A. F.; Andreae, M. O.; 2003. O mecanismo da floresta para fazer chover. Scientific American Brasil, 1(11): 38-45.

Artaxo, P.; Lara, L.B.L.S.; Pauliquevis, T.M. 2003. Dry and wet deposition in Amazonia: from natural biogenic aerosols to biomass burning impacts. IGAC Newsletter, 27: 12-16.

Artaxo, P. 2004. Mudanças climáticas globais e a Amazônia. Ciência Hoje, 35(206): 40-42.

Castanho, A. D. A.; Artaxo, P. 2001. Wintertime and summertime São Paulo aerosol source apportionment study. Atmospheric Environment, 35: 4.889 - 4.902.

Claeys, M.; Graham, B.; Vas, G.; Wang, W.; Vermeylen, R.; Pashynska, V.; Cafmeyer, J.; Guyon, P.; Andreae, M. O.; Artaxo, P.; Maenhaut W. 2004. Formation of secondary organic aerosols through photo-oxidation of isoprene. Science, 303: 1.173-1.176.

Cordova, A. M.; 2003. Gases traço na Amazônia: Variabilidade sazonal e temporal de $\mathrm{O}_{3}$, NOx e CO em ambientes de pastagem e floresta. Tese de doutorado, Instituto Astronômico, Geofísico e de Ciências Atmosféricas da USP (IAG/USP), São Paulo, São Paulo, 268 pp.

Cordova, A. M.; Gatti, L. V.; Longo, K.; Freitas, S.; Artaxo, P.; Procópio, A. S.; Silva Dias, M.A.F.; Freitas, E.D.; 2004. Nitrogen oxide measurements in an Amazon site and enhancements associated with a cold front. Atmospheric Chemistry and Physics Discussions, 4: 2.301-2.331.
Chadwick, O.A.; Derry, L.A.; Vitousek, P.M.; Huebert, B.J.; Hedin, L.O.1999. Changing sources of nutrients during four million years of ecosystem development. Nature 397: 491-497.

Davidson, E. A.; Artaxo, P. 2004. Globally significant changes in biological processes of the Amazon Basin: Results of the Large-scale Biosphere-Atmosphere Experiment. Global Change Biology 10: 1-11, doi: 10.1111/j.15298817.2003.00779.x.

Eck, T. F.; Holben, B. N.; Reid, J. S.; O'Neill, N. T.; Schafer, J.; Dubovik, O.; Smirnov, A.; Yamasoe, M.A.; Artaxo, P. 2003. High aerosol optical depth biomass burning events: a comparison of optical properties for different source regions. Geophysical Research Letters, 30(20): 2.035-2.048, doi: 10.1029/2003GL017861.

Falkovich, A.H.; Graber, E. R.; Schkolnik, G.; Rudich, Y.; Maenhaut, W.; Artaxo, P. 2004. Low molecular weight organic acids in aerosol particles from Rondônia, Brazil, during the biomass-burning, transition and wet periods. Atmospheric Chemistry and Physics Discussions (ACP), 4: 6.867-6.907.

Freitas, S. R.; 1999. Modelagem Numérica do Transporte e das Emissões de Gases Traços e Aerossóis de Queimadas no Cerrado e Floresta Tropical da América do Sul. Tese de Doutorado, Instituto de Física, Universidade de São Paulo, São Paulo, São Paulo, 204 p.

Freitas, S. R.; Longo, K. M.; Silva Dias, M. A. F.; Artaxo, P. 1997. Numerical modelling of air mass trajectories from the biomass burning areas of the Amazon basin. Annais da Academia Brasileira de Ciências, 68: 193-206.

Freitas, S. R.; Silva Dias, M. A. F.; Silva Dias, P. L.; Longo, K. M.; Artaxo, P.; Andreae, M. O.; Fischer, H. 2000a. A convective kinematic trajectory technique for low resolution atmospheric models. Journal of Geophysical Research, 105(D19): 24.375-24.386.

Freitas, S. R.; Silva Dias, M. A. F.; Silva Dias, P. L. 2000. Modeling the convective transport of trace gases by deep and moist convection. Hybrid Methods in Engineering, 2 (3): 317-330.

Freitas, S.R.; Longo, K. M.; Silva Dias, M. A.F.; Silva Dias, P. L.; Chatfield, R.; Prins, E.; Artaxo, P.; Recuero, F. 2004. Monitoring the transport of biomass burning emissions in South America. Environmental Fluid Mechanics, 5(1): 135167, DOI: 10.1007/s10652-005-0243-7.

Gash, J. H. C.; Nobre, C. A.; Roberts, J. M.; Victoria, R. L. 1996. Amazonian Deforestation and climate. John Wiley and Sons, Inglaterra.

Guenther, A.; Hewitt, C. N.; Erickson, D.; Fall, R.; Geron, C.; 1995. A global model of natural volatile organic compound emissions, Journal of Geophysical Research, 100: 8.873-8.892.

Guyon, P.; Graham, B.; Roberts, G. C.; Mayol-Bracero, O. L.; Maenhaut, W.; Artaxo, P.; Andreae, M. O. 2004. Sources of optically active aerosol particles over the Amazon forest. Atmospheric Environment, 38(7): 1.039-1.051, doi: 10.1016/ j.atmosenv.2003.10.051. 


\section{ACTA AMAZONICA}

Guyon, P.; Frank, G.; Welling, M.; Chand, D.; Artaxo, P.; Nishioka, G.; Rizzo, L. V.; Lloyd, J.; Kolle, O.; Silva Dias, M. A. F.; Gatti, L. V.; Cordova, A. M.; Andreae. M. O. 2005. Airborne measurements of trace gases and aerosol particles emissions from biomass burning in Amazonia. Atmospheric Chemistry and Physics Discussions, 5: 2.791-2.831.

Haywood, J.; Boucher, O. 2000. Estimates of the direct and indirect radiative forcing due to tropospheric aerosols: a review. Reviews of Geophysics, 38 (4): 513-543.

Holben, B.N.; Eck, T. F.; Slutsker, I.; Tanre, D.; Buis, J. P.; Setzer, A.; Vermote, E.; Reagan, J. A.; Kaufman, Y. J.; Nakajima, T.; Lavenu, F.; Jankowiak, I.; Smirnov, A. 1998. AERONET - A Federated Instrument Network and Data Archive for Aerosol Characterization. Remote Sensing of the Environment, 66: 1 - 16.

Jacob, D.J.; Wofsy, S. 1988. Photochemistry of biogenic emissions over the Amazon forest, Journal of Geophysical Research, 93(D2): 1.477-1.486.

Kaufman, Y.; Hobbs, P. V.; Kirchhoff, V.W. J. H.; Artaxo, P.; Remer, L.; Holben, B.N.; King, M. D.; Prins, E. M.; Ward, D. E.; Longo, K. M.; Mattos, L. F.; Nobre, C. A.; Spinhirne, J.; Thompson, A. M.; Gleason, J. F.; Christopher, S. A. 1998. The Smoke Cloud and Radiation Experiment in Brazil (SCAR-B). Journal of Geophysical Research, 103(D24): 31.783-31.808.

Kesselmeier, J.; Kuhn, U.; Wolf, A.; Andreae, M. O.; Ciccioli, P.; Brancaleoni, E.; Frattoni, M.; Guenther, A.; Greenberg, J.; Vasconcellos, P. C.; Oliva, T.; Tavares, T.; Artaxo, P. 2000. Atmospheric volatile organic compounds (VOC) at a remote tropical forest site in central Amazonia, Atmospheric Environment, 34, 4063 - 4072.

Krusche A.; Camargo, P.B.; Cerri, C.E.; Ballester, M.V.; Lara, B.L.S.L.; Victoria, R.L.; Martinelli, L.A. 2002. Acid rain and nitrogen deposition in a sub-tropical watershed (Piracicaba): ecosystems consequences. Environmental Pollution 121(3): 389-399.

Lacaux, J.P.; Artaxo, P. 2003. DEBITS: Past, present and future, International Global Atmospheric Chemistry Project - IGAC Newsletter, 27: 2-5.

Landulfo, E.; Papayannis, A.; Artaxo, P.; Castanho, A.D.A.; Freitas, A.Z.; Sousa, R.F.; Vieira Junior, N.D.; Jorge, M.P.M.P.; SánchezCcoyllo, O. R.; Moreira, D. S. 2003. Monitoring of Biomass Burning Aerosols over S. Paulo, Brazil using LIDAR, sunphotometer and satellite data. Atmospheric Physics and Chemistry (ACP), 3: 1523-1539.

Lara, L.B.L.S; Artaxo, P.; Martinelli, L. A.; Victoria, R. L.; Camargo, P. B.; Krusche, A.; Ayers, G.; Ferraz, E. S. B.; Ballester, M. V. 2001. Chemical composition of rainwater and land use changes in Piracicaba river basin: Southeast Brazil. Atmospheric Environment, 35: 4.937 - 4.945.

Lara, L.L., Holland, E.A.; Artaxo, P.; Camargo, P. B; Martinelli, L.A. 2005. Linking nitrogen deposition patterns and land use change in tropical areas. Biogeochemistry (in press).

Liousse, C.; Cachier, H.; Grégoire, J.M.; Penner, J.; Lavoué, D.; Hobbs, P.; Scholes, M.; Barbosa, P.; Andreae M. O.; Artaxo, P. 2004. Deriving global quantitative estimates for spatial and temporal distributions of biomass burning emissions. In: Granier, C.; Artaxo, P.; Reeves, C. (eds). Emissions of trace gases and aerosols into the atmosphere, Kluwer Academic Publishers, London, ISBN: 1-4020-2166-6.
Longo, K. M.; Thompson, A. M.; Kirchhoff, V. W. J. H.; Remer, L.; Freitas, S. R.; Silva Dias, M. A. F.; Artaxo, P.; Hart, W.; Spinhirne, J. D.; Yamasoe, M. A. 1999. Correlation between smoke and tropospheric ozone concentrations in Cuiabá during Smoke Clouds and radiation - Brazil (SCAR-B). Journal of Geophysical Research, 104(D10): 12.113-12.129.

Martinelli, L.A.; Piccolo, M.C.; Townsend, A.R.; Vitousek, P.M.;Cuevas, E.; McDowell, W.; Robertson, G.P.; Santos, O.C.; Treseder, K. 1999. Nitrogen stable isotopic composition of leaves and soil: Tropical versus temperate forests. Biogeochemistry, 46: 45-65.

Martins, J. V.; Artaxo, P.; Liousse, C.; Reid, J. S.; Hobbs, P. V.; Kaufman, Y. J. 1998. Effects of black carbon content, particle size and mixing on light absorption by aerosol particles from biomass burning in Brazil. Journal of Geophysical Research, 103(D24): 32.041-32.050.

Nobre, C. A.; Luizão, F.; Victoria, R.L.; Silva Dias, P.L.; Silva Dias, M.A.F.; Artaxo, P. 1996. The Large Scale BiosphereAtmosphere Experiment in Amazonia (LBA). LBA - Plano experimental conciso. INPE, Cachoeira Paulista, SP, Brazil.

Okin, G. S.; Mahowald, N.; Chadwick, O. A.; Artaxo, P. 2004. Impact of desert dust on the biogeochemistry of phosphorus in terrestrial ecosystems. Global Biogeochemical Cycles, 18, doi:10.1029/2003GB002145.

Procopio, A. S.; Remer, L. A.; Artaxo, P.; Kaufman, Y. J.; Holben, B. N. 2003. Modeled spectral optical properties for smoke aerosols in Amazonia. Geophysical Research Letters, 30(24): 2.265-2.270. doi: 10.1029/2003GL018063.

Procópio, A. S.; Artaxo, P.; Kaufman, Y. J.; Remer, L. A.; Schafer, J. S.; Holben, B. N. 2004. Multiyear analysis of Amazonian biomass burning smoke radiative forcing of climate. Geophysical Research Letters, 31(3) L03108-L03112, doi:10.1029/2003GL018646.

Ricchiazzi, P. 1998. SBDART: A Research and Teaching Software Tool for Plane-Parallel Radiative Transfer in the earth's Atmosphere. Bulletin of the American Meteorological Society, 79: 2.101-2.114.

Roberts, G. C.; Andreae, M. O.; Zhou J.; Artaxo, P. 2001. Cloud condensation nuclei in the Amazon basin: "marine conditions over a continent?, Geophysical Research Letters, 28(14): 2.807-2.810.

Rizzo, L. V. 2002. Modelamento de propriedades físicas $e$ químicas de aerossóis e suas interações com gases traços na Amazônia. Masters Thesis Instituto de Física da USP, São Paulo, São Paulo, 240 p.

Rissler, J.; Swietlicki, E.; Zhou, J.; Gatti, L. V.; Roberts, G.; Andreae, M. O.; Artaxo, P.; 2004. Physical properties of the submicrometer aerosol over the Amazon rain forest during the wet-to-dry season transition - Comparison of modeled and measured CCN concentrations. Atmospheric Chemistry and Physics, 4: 2.119-2.143.

Roberts, G.C.; Artaxo, P.; Zhou, J.; Swietlicki, E.; Andreae, M. O.; 2002. Sensitivity of CCN spectra on chemical and physical properties of aerosol: A case study from the Amazon Basin. Journal of Geophysical Research, 107(D20): 8.070-8.088, doi:10.1029/2001JD000583. 
Rosenfeld, D. 1999. TRMM Observed First Direct Evidence of Smoke from Forest Fires Inhibiting Rainfall. Geophysical Research Letters 26(20): 3.105-3.108.

Rosenfeld, D. 2000. Suppression of Rain and Snow by Urban and Industrial Air Pollution. Science, 287: 1.793-1.796.

Schafer, J. S.; Holben, B. N.; Eck, T. F.; Yamasoe, M. A.; Artaxo, P.; 2002a. Atmospheric effects on insolation in the Brazilian Amazon: Observed modification of solar radiation by clouds and smoke and derived single scattering albedo of fire aerosols, Journal of Geophysical Research, 107(D20): 8074, doi:10.1029/2001JD000428.

Schafer, J.S.; Eck, T.F.; Holben, B.N.; Artaxo, P.; Yamasoe, M. A.; Procopio, A.S. 2002b. Observed reductions of total solar irradiance by biomass-burning aerosols in the Brazilian Amazon and Zambian Savanna. Geophysical Research Letters, 29(17): 1.823, 10.1029/2001GL014309.

Schkolnik, G.; Falkovich, A. H.; Rudich, Y.; Maenhaut, W.; Artaxo, P. 2005. A New Analytical Method for the Determination of Levoglucosan, Saccharidic Compounds and 2methylerythritol and its Application to Smoke and Rainwater Samples. Environmental Science and Technology, 39(8): 2.744-2.752.

Silva Dias, M.A.F.; Rutledge, S.; Kabat, P.; Silva Dias, P. L.; Nobre, C.; Fisch, G.; Dolman, A.J.; Zipser, E.; Garstang, M.; Manzi, A.; Fuentes, J. D.; Rocha, H.; Marengo, J.; Plana-Fattori, A.; Sá, L.; Alvalá, R.; Andreae, M. O.; Artaxo, P.; Gielow, R.; Gatti, L. V. 2002. Clouds and rain processes in a biosphere atmosphere interaction context in the Amazon Region, Journal of Geophysical Research, 107(D20): 8.072-8.092, doi:10.1029/2001JD000335.

Silva Dias, M.A.F.; Artaxo, P.; Andreae, M. O. 2004. Aerosols impact clouds in the Amazon Basin. GEWEX Newsletter, 14(4): 4-6.

Trebs, I.; Metzger, S.; Meixner, F. X.; Helas, G.; Hoffer, A.; Rudich, Y.; Falkovich, A. H.; Moura, M. A. L.; Silva Jr., R. S.; Artaxo, P.; Slanina, J.; Andreae, M. O. 2005a. The $\mathrm{NH}_{4}^{+}-\mathrm{NO}_{3}{ }^{-}-\mathrm{Cl}^{-}-\mathrm{SO}_{4}^{2-}$. $\mathrm{H}_{2} \mathrm{O}$ aerosol system and its gas phase precursors at a pasture site in the Amazon Basin: How relevant are mineral cations and soluble organic acids?. Journal of Geophysical Research, 110: D07303, doi:10.1029/2004JD005478.
Trebs, I.; Lara, L. L.; Zeri, L. M. M.; Gatti, L. V.; Artaxo, P.; Dlugi, R.; Slanina, J.; Andreae, M. O.; Meiner, F. X. 2005b. Dry and wet deposition of inorganic nitrogen compounds to a tropical pasture site (Rondonia, Brazil). Atmospheric Chemistry and Physics, 5: 3.131-3.189.

Walko, R.; Band, L.; Baron, J.; Kittel, F.; Lammers, R.; Lee, T.; Ojima, D.; Pielke, R.; Taylor, C.; Tague, C.; Tremback, C.; Vidale, P. 2000. Coupled Atmosphere-Biophysics-Hydrology Models for Environmental Modeling. Journal of Applied Meteorology 39(6): 931-944.

Williams, M.R.; Fisher, T.R.; Melack, J.M. 1997. Chemical composition and deposition of rain in the central Amazon, Brazil. Atmospheric Environment, 31: 207-217.

Wiedinmyer, C.; Guenther, A.; Harley, P.; Hewitt, N.; Geron, C.; Artaxo, P.; Steinbrecher, R.; Rasmussen, R.; 2004. Global Organic Emissions from Vegetation. In: Granier, G.; Artaxo, P.; Reeves, C.; (eds). Emissions of trace gases and aerosols into the atmosphere, Kluwer Academic Publishers, London, ISBN: 1-4020-2166-6. pp.

Yamasoe, M. A.; 1999. Estudo de propriedades ópticas de partículas de aerossóis a partir de uma rede de radiômetros solares. PhD Thesis Instituto de Física da USP, São Paulo, São Paulo, 255p.

Yamasoe, M. A.; Artaxo, P.; Miguel, A. H.; Allen, A. G. 2000. Chemical composition of aerosol particles from direct emissions of biomass burning in the Amazon Basin: watersoluble species and trace elements. Atmospheric Environment, 34: 1.641-1.653.

Zhou, J.; Swietlicki, E.; Hansson, H. C.; Artaxo, P. 2002. Submicrometer aerosol particle size distribution and hygroscopic growth measured in the Amazon rain forest during the wet season, Journal of Geophysical Research, 107 (D20): 8.055-8.065, doi:10.1029/2000JD000203.

\section{RECEBIDO EM 13/08/2004 \\ ACEITO EM 22/11/2004}

